\section{Adrenal transplants for Huntington's disease?}

SIR-More than 100 patients with Parkinson's disease have been transplanted with adrenal medulla tissue into the ventricular wall of the caudate nucleus ${ }^{1-3}$. Although the results are controversial ${ }^{3}$, the original rationale was that the adrenal chromaffin cells when put into the brain would release dopamine in sufficient quantities to reverse the functional deficits produced by the disease, and was based on animal studies demonstrating some benefit using this technique in models of Parkinson's disease ${ }^{4-6}$.

Recently, Allen and his colleagues have performed an adrenal medulla autograft, but this time in a patient with Huntington's disease (Vanderbilt University Medical Center press release, 3 March 1988; see ref. 7). The rationale for doing this operation was apparently their unpublished finding that adrenal medulla transplants into rat caudate nucleus could protect against excitotoxin-induced neurodegeneration?. Their hypothesis appears to be that the adrenal grafts would protect against excitotoxin-induced neurodegeneration in Huntington's patients.

Although recent theory suggests that the neurodegeneration of the striatum in Huntington's disease may be related to the production of endogenous excitotoxins ${ }^{8}$, there is no proof for such a hypothesis. If further experiments were to substantiate the role of an excitotoxin in the aetiology of Huntington's disease and to substantiate the neuroprotective effect of adrenal transplants, then the rationale for the procedure would appear sound. But there is no published study demonstrating any beneficial effect of adrenal medulla transplants in animal models of Huntington's disease. Allen and his colleagues have reported that neonatal striatal tissue can protect against the excitotoxin-induced lesions ${ }^{9}$, although we have not been able to observe such an effect $^{10}$.

The use of transplantation techniques in the treatment of Huntington's disease is still in the investigative stage, requiring further extensive animal research. Indeed the adrenal transplant techniques could exacerbate a patient's condition. If the original rationale for using adrenal transplants in the treatment of Parkinson's disease is correct, namely the release of dopamine ${ }^{4,5}$, then it is possible that adrenal transplants could exacerbate the symptoms of Huntington's disease ${ }^{11,12}$. Furthermore, tissue transplanted into the caudate appears to disrupt the bloodbrain barrier ${ }^{13,14}$ and the consequences of this effect in Huntington's disease is unknown. In addition, some of the neurosurgical techniques used for the Parkinson's patients, such as making a cavity into the caudate', could result in facilitating the progression of the disease by removing some of the already degenerated caudate nucleus.

Huntington's disease is a severe neurodegenerative disorder that causes profound incapacity and eventual death ${ }^{12,13}$. As in most terminal diseases, there is always the temptation to try some unproven but hopeful treatment. But is it ethical to perform a treatment that has hardly been tested in animal models, and where the data have not been assessed in peer-reviewed journals, let alone replicated by other laboratories? These questions are especially pertinent in this case as the rationale for the procedure suggests that the adrenal transplant would be expected only to halt or slow the progression of the disease, and may not reverse the neurodegeneration already present. Although research into a surgical treatment for the disease has not progressed to a level that merits clinical application, it is an area of great potential.

The studies investigating fetal brain tissue transplants in animal models of the disease suggest that they may be beneficial. The transplanted fetal striatal-ridge tissue survives, grows, integrates, and produces recovery of function in the animals ${ }^{16,17}$. But many experiments need to be performed in rodents and non-human primates before clinical trials in humans are undertaken. Furthermore, the use of fetal tissue has its own ethical considerations $s^{3,17}$ and may not be a practical procedure for some time. Until animal experiments are performed by a number of institutions and have demonstrated that the procedure is likely to be of value, it is hoped that adrenal medulla autografting for Huntington's disease does not follow the same inappropriately accelerated course that is being seen with adrenal medulla transplants into the brains of patients with Parkinson's disease $^{3}$.

Paul R. Sanberg ANDREW B. NORMAN

Division of Neuroscience,

University of Cincinnati Medical Center,

Cincinnati,

Ohio 45267-0559, USA

1. Madrazo, I. et al. New Engl.J. Med. 316, 831 (1987).

2. Lindvall O et al. Ann. Neurol. 22, 455-468(1987).

3. Sladek. J.R. \& Shoulson, I. Science 240, 1386 (1988)

4. Freed, W J Biol Psychiat 18, 1205-1267 (1983).

Freed, W.J. Science 241, 275 (1988)

Sladek, J.R. \& Gash, D.M. J. Neurosurg. 68, 337 (1988) Science News 133, 268 (1988)

Sanberg, P.R. \& Johnston, G.A. Med. J. Austral. 2, 460 465 (1981)

Tulipan, N., Huang, S., Whetsell, W.O. \& Allen, G.S. Brain Res. 377, 163-167 (1986)

10. Nash, D.R., Kaplan, S.M. Norman, A.B. \& Sanberg, P.R. Soc. Neurosci. Abstr. (in the press).

11. Sanberg, P.R. \& Coyle, J.T. CRC Crit. Rev. Clin. Neurobiol. 1, 1-44 (1981).

12. Martin, J.B. \& Gusella, J.F. New Engl. J. Med. 315, 1267 $2732(1986)$

13. Norman, A.B. et al. Prog. Brain Res. (in the press)

14. Sanberg. P R etal Expl Neurol. (in the press).

14. Sanberg, P.R. et al. Expl Neurol. (in the press).

16. Sanberg. P.R., Calderon, S.F., Garver, D.L. \& Norman Sanberg, P.R., Calderon, S.F., Garver, D.L. \&
A.B. Psychopharmac. Bull. 23, 476-482 (1988). 17. Mahowald, M. B. et al. Science 235, 1307-1308 (1987)
Cystic fibrosis, fertility and birth intervals

SIR-The issue of heterozygote advantage associated with the recessive allele for cystic fibrosis (CF) has been discussed in Scientific Correspondence recently ${ }^{1-5}$. Reports of high sex ratio in affected fami$\operatorname{lies}^{6-8}$ and a negative relationship between sex ratio and parity ${ }^{8}$ suggest an effect on fertility, although claims for increased family size are rightly discounted on the grounds that recessive alleles are most frequently detected in large families ${ }^{9-11}$. Any effect on reproduction must almost certainly operate through one sex only ${ }^{1,7,8}$, but an apparent association between the mutant haplotype and the $\mathrm{Y}$ chromosome ${ }^{2}$ has not been confirmed ${ }^{3.4}$. Many alternative, or additional, explanations have been offered (see ref. 11).

The most careful analysis of fertility is that of Jorde and Lathrop", in which the families of grandparents of patients were compared with precisely matched controls. Uncorrected figures show an apparently increased family size associated with the $\mathrm{CF}$ allele, but this was negated by correction for ascertainment bias. Mean and median birth intervals were also not significantly different from those of controls, but comparison of values from carriers with 20 sets of controls shows that in 19 cases both the average interval between marriage and the first birth and the average interval between subsequent births was shorter in the carrier families. This proportion indicates a highly significant difference $\left(P<1 \times 10^{-4}\right)$ in the first and subsequent birth intervals.

Using the authors' own figures it can be calculated that in an average family of four children, in which one parent is a $\mathrm{CF}$ carrier, the $\mathrm{CF}$ allele is replicated more than 5 per cent faster than its normal homologue in a control family. Jorde and Lathrop ascribe this difference to the superior fertility of families selected on the basis of expression of a recessive allele, but did not check or elaborate on their assumption.

A carefully controlled comparison of birth intervals in carrier and normal families of similar size should be informative, as this would eliminate the ascertainment bias associated with family size.

D.J. PRITCHARD

Department of Human Genetics, The University of Newcastle upon Tyne, Newcastle upon Tyne NE2 4AA, UK

1. Pritchard, D.J. Nature 330, 319 (1987)

Kitzis, A et al Nature 333, $215(1988)$

Ten Kate, L.P. et al. Nature 334, 20 (1988).

Tümmler, B. et al. Nature 334, 110 (1988).

Gibson, J.P. Nature 334, 20 (1988)

Danks, D.M. et al. Ann. hum. Genet. 28, 323-356 (1965).

Gloria-Bottini, F. et al. Hum. Genet. 54, 79-82 (1980)

Pritchard, D.J. et al. Archs Dis. Childhood 58, $290(1983)$

Ten Kate, L.P. Ann. Hum. Genet. 40, 287-297 (1977).

10. Wright, S. W \& Morton. N. E. Am. J hum. Genet. 20,157$169(1988)$.

1. Jorde. L.B. \& Lathrop, G.H. Am. J. hum. Genet. 42, 808 $815(1988)$ 